MATEC Web of Conferences 47, 01002 (2016)

DOI: $10.1051 /$ matecconf/20164701002

(C) Owned by the authors, published by EDP Sciences, 2016

\title{
Flexural Toughness of Ring-Shaped Waste Bottle Fiber Concrete
}

\author{
S. K. Faisal ${ }^{1, a}$, J. M. Irwan ${ }^{1}$, N. Othman ${ }^{2}$ and M. H Wan Ibrahim ${ }^{1}$ \\ ${ }^{1}$ Jamilus Research Centre, Universiti Tun Hussein Onn Malaysia, 86400 Parit Raja, Johor, Malaysia \\ ${ }^{2}$ Micropollutant Research Centre, Universiti Tun Hussein Onn Malaysia, 86400 Parit Raja, Johor, Malaysia
}

\begin{abstract}
Polyethylene terephthalate (PET) bottles are plastic containers that are typically discarded, and thus, cause environmental pollution. To solve this problem, PET bottles are recycled incorporating with concrete. A ring-shaped PET (RPET) fiber are introduced in this study and designed with a special shape to mobilize fiber yielding rather than fiber pullout. Therefore, aim of this paper is to investigate the influence of RPET bottles fibre in terms of toughness strength. The width of RPET fibers is fixed at 5 and $10 \mathrm{~mm}$ and the loads were applied to the third points of the specimen. The experiment indicates that RPET- 5 and RPET$10 \mathrm{FC}$ presented an increase in the toughness index of $I_{20}$ on averages of $23.1 \%$ and $39.9 \%$ respectively, compared to normal specimens. It can conclude that incorporating RPET fiber in concrete presents significant improved of concrete properties.
\end{abstract}

\section{Introduction}

Polyethylene terephthalate (PET) is one of potential waste which could be used in various applications. Efforts have been made to explore their usage in concrete and one of that is fibre incorporating with concrete [1-3]. Silva et al. [3] mentioned that recycled manufactured monofilament PET fibres increases the toughness indexes of cementitious composites. It is due to the improvement the interfacial bond between fibre and cement. The author used mechanical indentations that create on the fibre surface by pressing the fibre between two hardened steel surfaces. Other authors [4] used embossed type PET fibre reporting that fibre concrete allows a mid-span deflection that is four times higher compared to the plain concrete. This is due to the improvement of interfacial friction energy that gives extra pull-out and friction load resistance in concrete. Ochi et al. [5] mentioned that the used of $30 \mathrm{~mm}$ long if intended PET fibres can lead to a flexural strength increase for volume replacements up to $1.5 \%$ compared to $20 \mathrm{~mm}$ length of fibre. These authors claim that long fibre has a capability interlocking fibre bridge in concrete due to long fibre that could be inserted between aggregates compared to $20 \mathrm{~mm}$ length of fibre. Ramadeviet al. [6] studied the possibility of using the waste PET bottle as the partial replacement of aggregate in Portland cement with fibre replacement content $1 \%$, $2 \%, 4 \%$ and $6 \%$. The finding revealed that the specimens with replacement of fine aggregate with PET bottle fibre increases gradually in flexural strength with increased fibre content. However, the author mentioned that $1 \%$ to $2 \%$ replacement are reasonable volume fibre content to achieve the optimum strength compared to the other fibre content on average $3.5 \%$ to $9.2 \%$ significant influence.

\footnotetext{
${ }^{a}$ Corresponding author : faisalsh@uthm.edu.my
} 
Choi et al. [7] studied performance ring type steel fibre concrete to determine the flexural toughness indices with fibre content from $0.2 \%$ to $0.8 \%$. The author mentioned that ring type steel fibre showed effectiveness and superiority to flexural behaviour ring type steel fibre concrete over the straight steel fibre with performs on average $45 \%$. Pelisseret al.[8] reported that recycle bottle PET with lengths 10,15 , and $20 \mathrm{~mm}$ and fibre content of $0.05 \%, 0.18 \%$ and $0.30 \%$ presents significant improved properties of concrete. The author founds that $20 \mathrm{~mm}$ long PET fibre show significant result on average $10.1 \%$ of flexural indices $I_{20}$. Meanwhile, the addition of recycled PET fibre enhanced absorption and toughness characteristic of concrete on average $4.44 \%$ of fibre content from $0.18 \%$ to $0.30 \%$.The author also claimed that increased fibre content above than $0.5 \%$ indicated that fibre did not affect the flexural toughness compared to the normal concrete. It can be concluded that previous studied [4-6] show capabilities of PET incorporating concrete in term of toughness strength.

Therefore, experiment presents the ring shaped waste bottle (RPET) as fiber concrete. The aim of this experiment is to investigate the influence of ring type of recycled (RPET) bottles fibre in terms of toughness strength according effect of fiber content RPET fiber, and effect of size RPET fiber.

\section{Experimental Program}

The cement used in all mixtures was a commercially available Portland cement (PC), which corresponds to MS 522: 2007 [9]. The aggregates and fine sand from the same local source were used. The aggregate size was $19 \mathrm{~mm}$ and maximum size of fine aggregates conforming to BS EN 12620 [10] is $4.75 \mathrm{~mm}$. Fly ash was used in this experiment with $15 \%$ additional from Portland cement volume used. The water binder ratio was kept constant at 0.55 . RPET FC was basically prepared by adopting the mixing procedure proposed by Liao et al. [11] and Irwan et al. [12]. RPET fibres are made directly from waste bottle as shown in Figure 1.

Waste bottles were cleaned to remove impurities. The waste bottle has been cut manually in a ring shaped. The diameter of the RPET bottles was fixed at $60 \pm 5 \mathrm{~mm}$. The width of RPET fiber was fixed at 5 and $10 \mathrm{~mm}$ as shown in Figure 2. The concrete mixture was tested to determine the concrete property of toughness strength according to ASTM C1018-97 [13]. All concrete specimens containing seven different content of RPET fiber were tested after 28 days. A steady rate of cross-head displacement at $0.05 \mathrm{~mm} / \mathrm{min}$ was used. Two rollers were employed as support for the specimens, and the loads were applied on the third points of the specimen. Net deflection was measured with a linear variable differential transducer (LVDT) on both sides of the specimen. The LVDT was connected to data saved in a computer. Figure 3 shows complete setup for the flexural experiment.
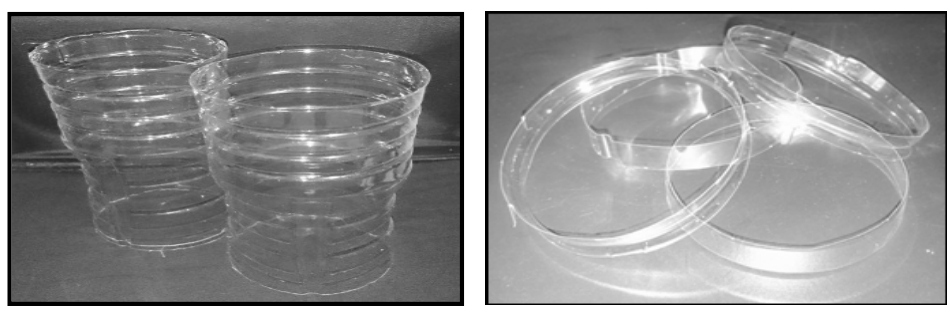

Figure 1. The ring bottle of plastic PET bottle.
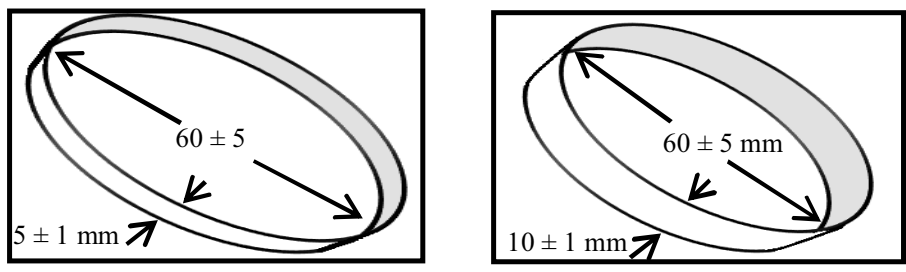

Figure 2. The dimension of ring waste bottles. 


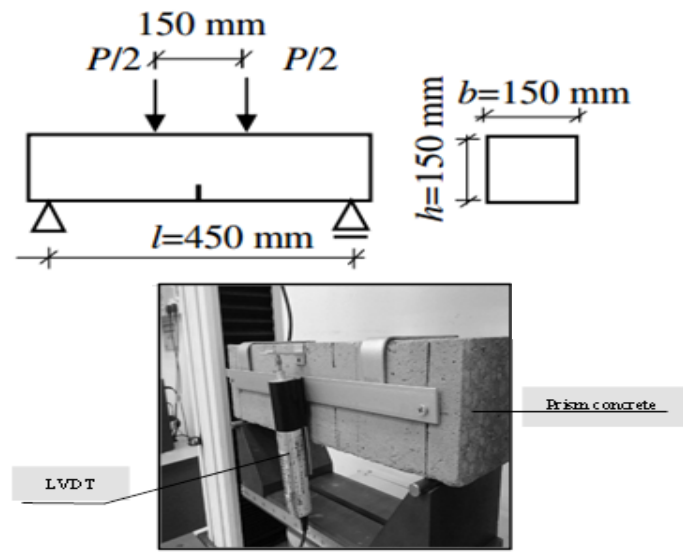

Figure 3. Specimen under third point loading.

\section{Result and Discussions}

The typical load-deflection response of normal specimen, as well as of RPET-5 and RPET-10 FC, is shown in Figures 4 and 5. A comparison was made between normal and RPET FC specimens, which showed the post-peak response that differentiated normal from RPET FC. Normal specimen behavior in load-deflection is brittle. A crack self-propagates when the strain energy was sufficiently high. Thus, a fracture occurred nearly instantaneously once peak load was reached. This finding is attributed to the tremendous amount of energy being released. RPET fiber in concrete exhibited the fiber bridging effect that helps control the energy release rate. Thus, RPET fiber in concrete can carry the load even after the peak.

The result based on the mentioned figures confirmed that RPET fibers in concrete exhibit a double-peak response in all fiber sizes as shown in Figure 4. Prior to the peak, the load increased proportionally as deflection increased. At the peak (concrete cracking), the load slightly decreased before the fibers began to take over, which caused the load to gradually decrease. In normal specimen, the point of concrete cracking indicates the point of failure or the peak point of the load, and then, the load gradually decreases as deflection increases. This pattern agrees with the finding of Piti [14] who studied the toughness of Polypropylene, PPfiber beams under bending. Piti [14] used $58 \mathrm{~mm}$-long rectangular fibers. The author found that incorporating PP macro fibers into concrete can carry the load after the peak load and double-peak response occurs during load deflection.

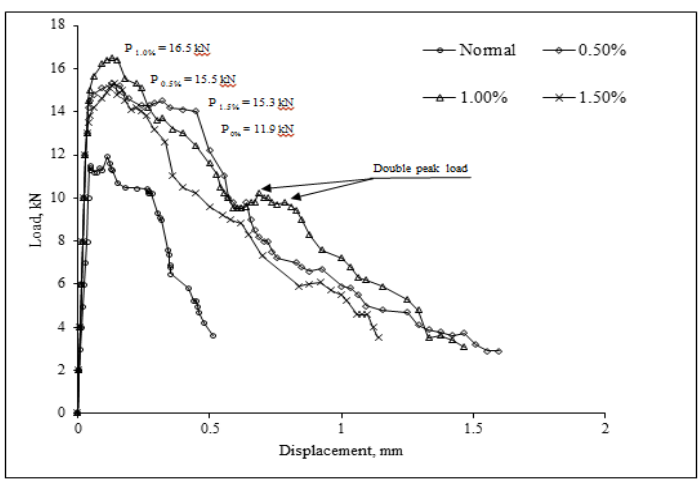

Figure 4. Load-displacement of RPET-5.

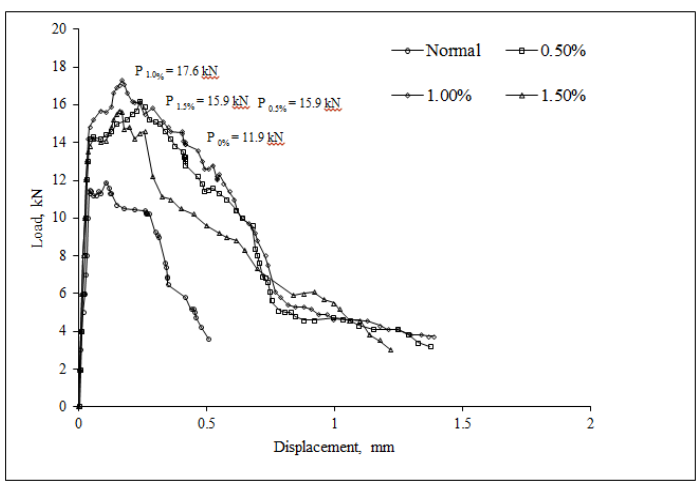

Figure 5. Load-displacement of RPET-10 FC. 


\subsection{Effect of RPET fiber content on flexural toughness}

Figures 6 and 7 show the average value of the toughness indices for RPET-5 and RPET-10 FC, respectively. The toughness indices $I_{5}, I_{10}$, and $I_{20}$ for normal specimen are 4.96and 12.87, respectively, as shown in Table 1. Adding 0.5\% RPET fiber caused small increase of 5.26 in toughness indices, $I_{5}, I_{10}$, and $I_{20}$, respectively, for RPET-5 FC. Meanwhile, RPET-10 FC obtained $5.29,10.87$, and 14.81 . The finding shows a small fiber content similar to that of normal at pre-peak loading or $I_{5}[7]$.

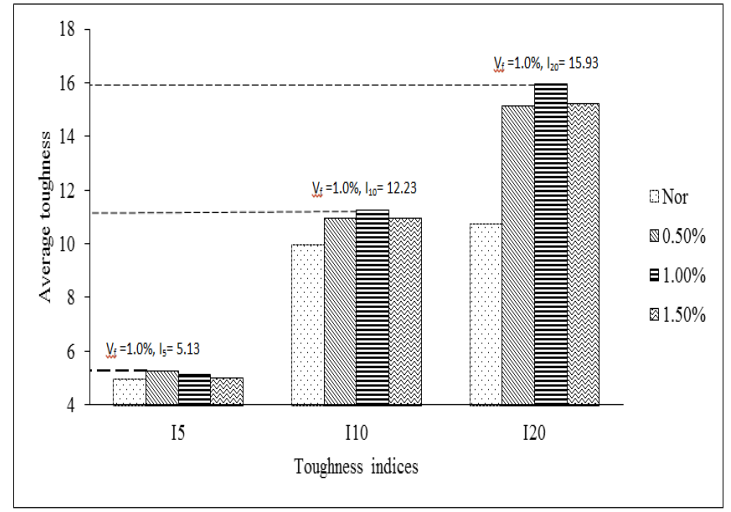

Figure 6. Flexural toughness of RPET-5 FC

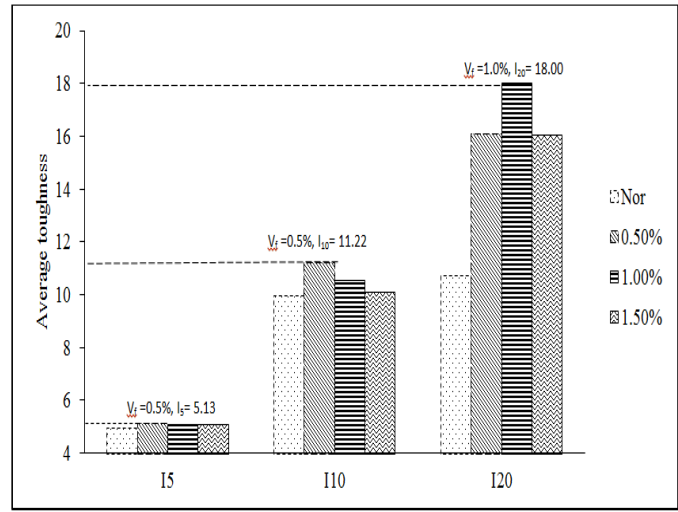

Figure 7. Flexural toughness of RPET-10 FC

The finding also indicated that increasing fiber content in concrete increases the toughness of concrete. The toughness indices $I_{5}, I_{10}$, and $I_{20}$ for RPET-5, with an average of $1 \%$ fiber content, are $5.13,11.23$, and 15.84 , respectively compared to normal specimen, whereas RPET-10 FC obtained values of $5.09,10.19$, and 17.26, respectively compared to normal specimen.

The experiment indicates that RPET-5 presented an increase in toughness index, $I_{20}$ of $17.5 \%$, $23.1 \%$, and $17.5 \%$ for $0.5 \%, 1.0 \%$ and $1.5 \%$ fiber content, respectively, compared with that of normal specimen as shown in Table 1. RPET-10 presented an increase in toughness index, $I_{20}$ of 35.7\%, $39.9 \%$, and $24.6 \%$ for $0.5 \%, 1.0 \%$ and $1.5 \%$ fiber content, respectively, compared with that of normal specimen.

Table 1. Analysis of toughness indices from flexural toughness test.

\begin{tabular}{|c|c|c|c|c|c|c|c|}
\hline \multirow{3}{*}{ Fiber } & \multirow{3}{*}{$\begin{array}{c}\text { Fiber } \\
\text { content, } \\
\%\end{array}$} & \multicolumn{6}{|c|}{ Flexural toughness indices } \\
\hline & & \multirow[t]{2}{*}{$I_{5}$} & \multirow{2}{*}{$I_{10}$} & \multirow[t]{2}{*}{$I_{20}$} & \multicolumn{3}{|c|}{$\begin{array}{c}\text { Difference percentage compared } \\
\text { to normal, }(\%)\end{array}$} \\
\hline & & & & & $I_{5}$ & $I_{10}$ & $I_{20}$ \\
\hline \multirow{7}{*}{ RPET-5 } & 0 & 4.96 & 9.94 & 12.87 & 0 & 0 & 0 \\
\hline & 0.25 & 5.29 & 10.81 & 13.96 & 6.7 & 8.8 & 8.5 \\
\hline & 0.50 & 5.26 & 10.95 & 15.12 & 6.0 & 10.2 & 17.5 \\
\hline & 0.75 & 5.09 & 11.21 & 15.70 & 2.6 & 12.8 & 22.0 \\
\hline & 1.00 & 5.13 & 11.23 & 15.84 & 3.4 & 13.0 & 23.1 \\
\hline & 1.25 & 5.07 & 11.04 & 15.76 & 2.2 & 11.1 & 22.5 \\
\hline & 1.50 & 5.02 & 10.96 & 15.12 & 1.2 & 10.3 & 17.5 \\
\hline \multirow{7}{*}{$\begin{array}{l}\text { RPET- } \\
10\end{array}$} & 0 & 4.96 & 9.94 & 12.87 & 0 & 0 & 0 \\
\hline & 0.25 & 5.29 & 10.22 & 14.81 & 6.7 & 2.8 & 15.1 \\
\hline & 0.50 & 5.13 & 11.22 & 17.47 & 3.4 & 12.9 & 35.7 \\
\hline & 0.75 & 5.16 & 10.89 & 17.72 & 4.0 & 9.6 & 37.7 \\
\hline & 1.00 & 5.09 & 10.52 & 18.00 & 2.6 & 5.8 & 39.9 \\
\hline & 1.25 & 5.12 & 10.19 & 17.26 & 3.2 & 2.5 & 34.1 \\
\hline & 1.50 & 5.06 & 10.09 & 16.03 & 2.0 & 1.5 & 24.6 \\
\hline
\end{tabular}


Thus, the mechanism of ring-shaped fibers in concrete indicates significant results. Ring-shaped PET fibers provide individual maximum tensile strength by yielding to concrete ruptures [7, 15]. Present study exhibited an increase ranged of $18.6 \%$ to $23.8 \%$ and $35.7 \%$ to $39.9 \%$ in the toughness $I_{20}$ index at $1.0 \%$ and $1.5 \%$ fiber contents, respectively, compared to normal specimen for all size of RPET fiber.

The present study was related to Choi et al. [7] study. Choi et al. [7] presented that ring-shaped steel fibers performed $45 \%$ better on average than straight and hooked steel fibers in terms of the toughness index $I_{20}$. An increase of fiber content leads to improvethe flexural toughness of FC. High fiber content would result in a high amount of fibers crossing a fractured section, and thus, improved failure mechanisms could be mobilized.

\subsection{Effect of RPET fiber size on flexural toughness}

Based on Figure 8, RPET-10 FC obtained a higher average of $2.9 \%$ toughness than RPET-5 FC. It is shows that RPET-10 FC exhibited higher in toughness indices with ranged of $2 \%$ to $4.3 \%$ compared to RPET-5 FC.

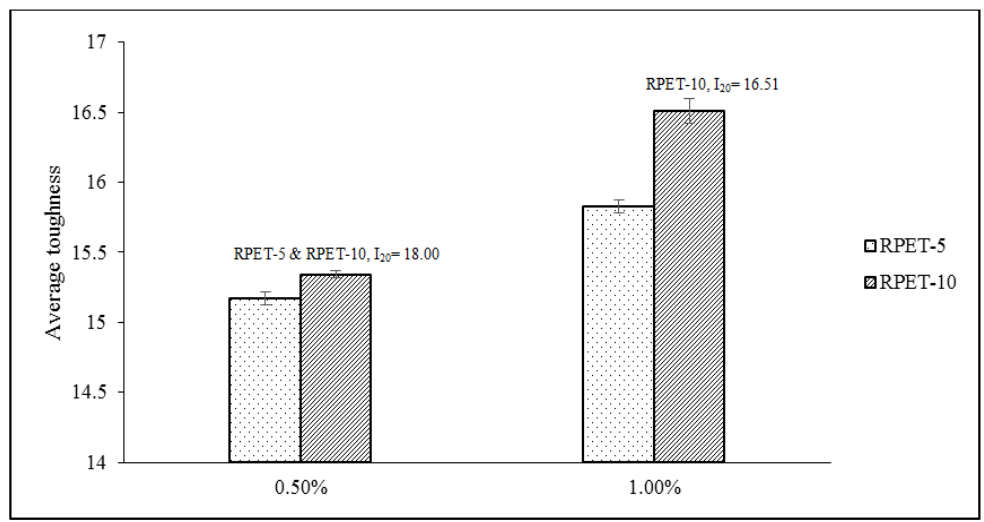

Figure 8. Toughness Indices $I_{20}$ of $0.50 \%$ and $1.00 \%$ fiber content.

Therefore, the present study indicated in line pattern results with Pelisseret al. [8]. The authors found that adding fibers from recycled PET bottles enhances the energy absorption rate and toughness of concrete under flexural load [8]. The $20 \mathrm{~mm}$-long fibers caused an increase of $44 \%$ in toughness of the $I_{20}$ index compared with the $10 \mathrm{~mm}$-long fibers at $0.18 \%$ fiber content. Meanwhile, the $20 \mathrm{~mm}$ long of fibers resulted in an increase of $30.8 \%$ in the $I_{20}$ toughness index compared with the $10 \mathrm{~mm}$ long fibers at $0.3 \%$ fiber content. Present study and observed by Pelisseret al. [8] claimed that the size of the fiber area contributes significantly to the toughness indices. Increasing the length of the fibers increases the size of the fiber area that connects to the cement matrix, and thus, contributes to the positive results in the toughness indices, particularly in $I_{10}$ and $I_{20}$.

\section{Conclusions}

The experiment indicates that RPET-5 and RPET-10FCpresented an increase in toughness index of $I_{20}$ on averages of $23.1 \%$ and $39.9 \%$ respectively, compared to normal specimens. This experiment exhibited that the RPET-10 FC presented improvement results compared with RPET-5 because of the size of the surface area that is in contact with concrete. RPET-10 FC presented an increase in toughness index, $I_{20}$ of $7.3 \%$ compared to RPET-5 FC. 


\section{Acknowledgement}

This work was financially supported by University Tun Hussein Onn Malaysia (UTHM) and Minister of Education Malaysia (KPM) through Exploratory Research Grant Scheme (ERGS) Vot. No. E-002.

\section{References}

[1] P. Agamuthu and P.N. Faizura, Biodegradability of degradable plastic waste, Waste management, 23(2), 95-100, (2005).

[2] A.A. Al-Manaseer, T.R. Dalal, Concrete containing plastic aggregates, Concrete International, 19(8), 47-52, (1997).

[3] D.A. da Silva, A.M. Betioli, P.J.P. Gleize, H.R.Roman, L.A. Gomez and J.L.D. Ribeiro, Degradation of recycled PET fibres in Portland cement-based materials, Cement and Concrete Research, 35(9), 1741-1746, (2005).

[4] F. Fraternali, V. Ciancia, R. Chechile, G. Rizzano, L. Feo and L. Incarnato, Experimental study of thermo-mechanical properties of recycled pet fiber-reinforced concrete, Composites Structures, 93(9), 2368-2374, (2011).

[5] T. Ochi, S. Okubo and K. Fukui, Development of recycled PET fibre and its application as concrete-reinforcing fibre, Cement Concrete Composite, 29(6), 448-455, (2007).

[6] K. Ramadevi and R. Manju, Experimental investigation on the properties of concrete with plastic PET fibre as fine aggregates, International Journal of Emerging Technology and Advanced Engineering, 2, 2250-2459, (2012).

[7] O.C. Choi and C. Lee, Flexural performance of ring type steel fibre reinforced concrete, Cement and Concrete Research, 33(6), 841-849, (2003).

[8] P. Fernando, O.R.K. Montedo, P.J.P. Gleize and H. R. Roman, Mechanical properties of recycled PET fibres in concrete, Materials research, 15(4), 679-686, (2012).

[9] MS EN 196-1, Specification for Portland Cement Composites, Department of Standards Malaysia, ( 2007).

[10] Eurocode 2, Aggregate for concrete, EN 12620, British Standard Institution, London, (2002).

[11]W. Liao, S. Chao and A. Naaman, Experience self-consolidating high performance fibre reinforced mortar and concrete, American Concrete Institution, 274(6), 79-94, (2010).

[12] J.M. Irwan, R.M. Asyraf, N. Othman, H.B. Koh, A.K. Aeslina, M.M.K. Annas, and S. K. Faisal, Deflection behaviour of irregular-shaped polyethylene terephthalate fibre reinforced concrete beam, Advanced Materials Research, 911, 438-442, (2014).

[13]ASTM C1018-97, Standard test method for flexural toughness and first crack load strength of fiber reinforced concrete, The American Society for Testing and Materials Standard, (2006).

[14]S. Piti, Toughness evaluation of steel and polypropylene fiber reinforced concrete beams under bending, Science Technology, 9(3), 35-41, (2004).

[15]D. Foti, Preliminary analysis of concrete reinforced with waste bottles pet fibers, Construction and Building Materials, 25, 1906-1915, (2011). 